\title{
The genus Prorops Waterson, 1923 (Hymenoptera, Bethylidae) from Madagascar
}

\author{
Cecília WAICHERT ${ }^{1} \&$ Celso O. AZEVEDO ${ }^{2}$ \\ ${ }^{1}$ Utah State University, Department of Biology, 5305 Old Main Hill, Logan, Utah, USA, 84322-5305. \\ E-mail: cwaichert@gmail.com \\ ${ }^{2}$ Universidade Federal do Espírito Santo, Departamento de Biologia, Av. Marechal Campos, 468, \\ 29040-090 Vitória, ES, Brazil. E-mail: bethylidae@gmail.com
}

\begin{abstract}
Three species of the genus Prorops Waterson, 1923 occur in Madagascar. Prorops nasuta Waterson, 1923 is recorded for the first time from Madagascar and two new species are described and illustrated: P. sparsa sp. nov. and P. impotens sp. nov., both based on the morphology of males and females. A brief discussion of the status of the genus, illustrations, and a key to Madagascan species of Prorops are provided.
\end{abstract}

Keywords. Bethylid, Epyrinae, Sclerodermini, new species, new occurrence.

Waichert C. \& Azevedo C.O. 2012. The genus Prorops Waterson, 1923 (Hymenoptera, Bethylidae) from Madagascar. European Journal of Taxonomy 16: 1-11. http://dx.doi.org/10.5852/ejt.2012.16

\section{Introduction}

The genus Prorops is composed of five species and is distributed throughout the New World and the Ethiopian, Oriental, and Palaearctic regions. It was described by Waterson (1923) to include a single African species, $P$. nasuta. The name refers to the elongated frontal process, similar to that seen in soldiers of termites. Evans (1977) added two species from the Americas to the genus: P. obsoleta and P. petila; Terayama (2006) described P. rakan, a Palaearctic species; and recently, Lim \& Lee (2011) added the first Oriental taxon, P. mandibularis Lim, 2011.

Specimens of Prorops are recognized by having an elongated frontal process, covering the clypeus and the antennal base. The mandibles are especially large compared to other bethylid species and are obliquely cut distally on the ventral edge, with three teeth (Evans 1964). Species in the genus Prorops are tiny wasps approximately $2 \mathrm{~mm}$ long with scarce body sculptures, such as carina and sulci. All species are alate, though veins are reduced. All five species have been distinguished by patterns of veins in the forewing and the length and shape of the frontal process and the head.

Prorops nasuta is the only species for which information on ecology and host use is available. It has been studied in different economic contexts since its description. The species is a parasitoid of the curculionid Stephanoderes hampei Ferrari, 1871, the most important pest of coffee worldwide (Murphy \&Moore 1990). Thus, P. nasuta has been introduced along with another bethylid, Cephalonomia stephanoderis Betrem, 1961, in different countries for biological control of the coffee borer (Pérez-Lachaud \& Hardy 
1999). Despite their potential application, there are no records or studies of the hosts of the other species of Prorops and they have thus far not been used for biological control.

Recent surveys in poorly studied areas such as Madagascar have shown that the genus is more speciose than previously thought. Prorops was recorded from Madagascar by Mugrabi \& Azevedo (2011) at the generic level, but species occurring in the area were not listed. Here, we describe two new species from Madagascar and record P. nasuta Waterson for the first time from the island. Characters from male genitalia are discussed for the first time for the genus and a key to the males and females of the three species is presented.

\title{
Material and methods
}

The material examined in this study was provided by Robert Zuparko, California Academy of Science, San Francisco, U.S. (CASC). It was collected by the project "Terrestrial Arthropod Inventory of Madagascar", grant \#BSI 0072713, which was coordinated by Dr. Brian Fisher.

Morphological analyses were based on direct examination of specimens under a Leica M125 dissection microscope. Structural terminology follows Evans (1964) and Azevedo (1999), but terminology related to the integument sculpture follows Harris (1979).

Measurements and indices used are as follows: body length, measured from the apex of clypeus to the posterior margin of the last metasomal segment, excluding male genitalia or female sting; DAO, diameter of anterior ocellus, measured in frontal view; distance of posterior ocellus to vertex, measured in dorso-posterior view; HE, height of eye, measured in lateral view, across its maximum height (length); $\mathrm{LH}$, length of head, measured in frontal view, from vertex crest to the median apical margin of clypeus; OOL, ocello-ocular line, measured in latero-dorsal view, the shortest distance from the eye top to the posterior ocellus; VOL, vertex-ocular line, measured in dorsal view, distance from the top of the eye to the vertex crest; WF, width of frons, measured in frontal view, its minimum width, usually about the ventral margin of the eyes; $\mathrm{WH}$, width of head, measured in frontal view, its maximum width including eyes; and WOT, width of ocellar triangle, measured in frontal view, maximum width, including ocelli.

\section{Results}

\author{
Classis Hexapoda Blainville, 1816 \\ Ordo Hymenoptera Linnaeus, 1758 \\ Subordo Apocrita Latreille, 1810 \\ Superfamilia Chrysidoidea Linnaeus, 1761 \\ Familia Bethylidae Latreille, 1802 \\ Subfamilia Epyrinae Westwood, 1832 \\ Tribe Sclerodermini Kieffer, 1914 \\ Genus Prorops Waterson, 1923
}

Prorops sparsa sp. nov.

(Figs. 1A, 2A-H, 3A-D)

\section{Etymology}

The specific epithet refers to each side of the frontal process being widely separated from each other. 

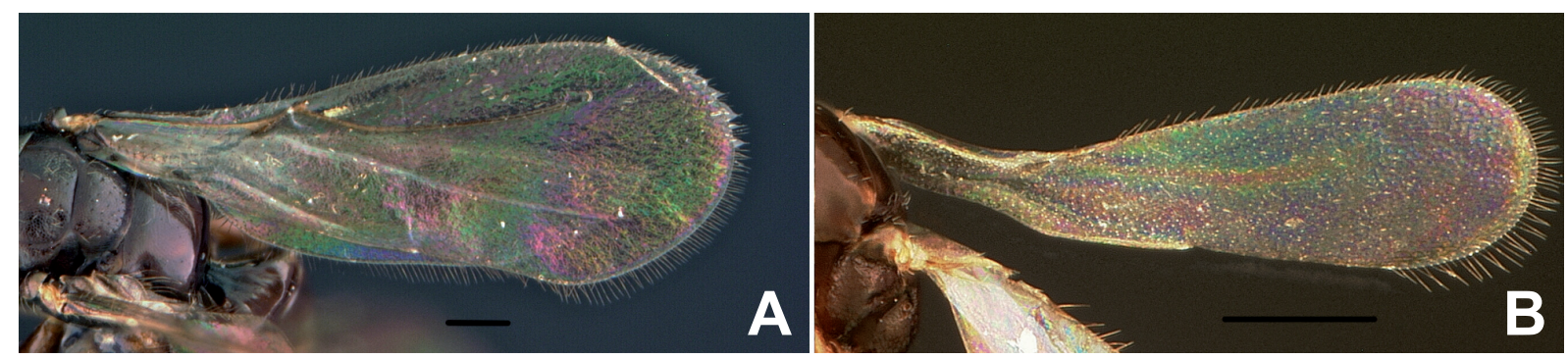

Fig. 1. Wing venation. A. Prorops sparsa sp. nov. Forewing, ㅇ. B. Prorops impotens sp. nov. Forewing, O. - Scale $=0.2 \mathrm{~mm}$.

Material examined (all from Madagascar)

\title{
Holotype
}

đ., Province Diego-Suarez, Parc National Montagne d'Ambre, elevation 975 m, 21-25 Jan. 2001, $12^{\circ} 31^{\prime} S 49^{\circ} 11^{\prime} E$, Malaise trap, M.E. Irwin, E.I. Schlinger \& R. Harin'Hala coll., CASENT 2085165 (CASC).

\author{
Allotype \\ 9, Toamasina Province, botanic garden, near entrance to Andasibe National Park, elevation $1025 \mathrm{~m}$, \\ 8-16 Oct. 2001, $18^{\circ} 55^{\prime} 58^{\prime \prime}$ S 48²4’47’'E, Malaise trap, R. Harin'Hala coll., CASENT 2085656.
}

\section{Paratypes}

Province Diego-Suarez, Parc National Montagne d'Ambre, 1 q, elevation 960 m, 19 Mar.-5 Apr. 2001, 12 $30^{\prime} 52$ 'S 49 $19^{\prime} 53$ "E, Malaise trap, R. Harin'Hala coll., CASENT 2064739;

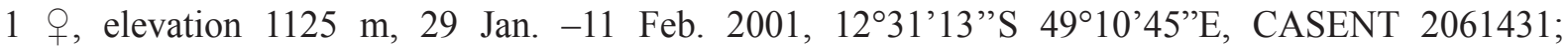
1 o, 14-30 May 2001, CASENT 2085213; $1 \hat{\jmath}$, Province Fianarantsoa, Parc National Ranomafana, radio tower at forest edge, elevation $1130 \mathrm{~m}, 24$ May-4 Jun. 2002, 21 ${ }^{\circ} 15^{\prime} 05^{\prime} \mathrm{S}$ 47²4'43"E, Malaise trap, mixed tropical forest, R. Harin'Hala coll., CASENT 2086155; 1 q, Parc National Ranomafana, Belle Vue at Talatakely, elevation 1020 m, 22-28 Sep. 2001, 21 ${ }^{\circ} 15.99^{\prime}$ S $47^{\circ} 25.21^{\prime} \mathrm{E}$, Malaise trap, secondary tropical forest, R. Harin'Hala coll., CASENT 2078329; 1 , Vohiparara, at brokenbridge, elevation 1110 m, 25 Jul. -3 Aug. 2002, 21 ${ }^{\circ} 13.57^{\prime} \mathrm{S} 47^{\circ} 22.19^{\prime} \mathrm{E}$, Malaise trap in high altitude, rainforest, R. Harin'Hala coll., CASENT 2064096.

\section{Diagnosis}

This species is recognized by having a dark castaneous color; the wing is hyaline; the head is wider than long; the mandible broad and flat; the clypeus is short and wide with the median lobe rounded; the frontal process is elongated and separated; the mesoscutum has parapsidal sulcus almost complete; the propodeum without carina; and the forewing has radial vein (Fig. 1A).

\section{Differential diagnosis}

This species is unique among Prorops by having the frontal process entirely divided into two arms (Fig. $2 \mathrm{~A}, \mathrm{G})$. Additionally, this species can be differentiated from the others by having the anterior margin of the pronotal disc sharp and medially depressed. The propodeal disc is fully ecarinate, which is an unusual feature in species of Prorops.

\section{Description}

Holotype, $\widehat{\partial}$. Body length $2.27 \mathrm{~mm}$. Forewing length $1.92 \mathrm{~mm}$. 

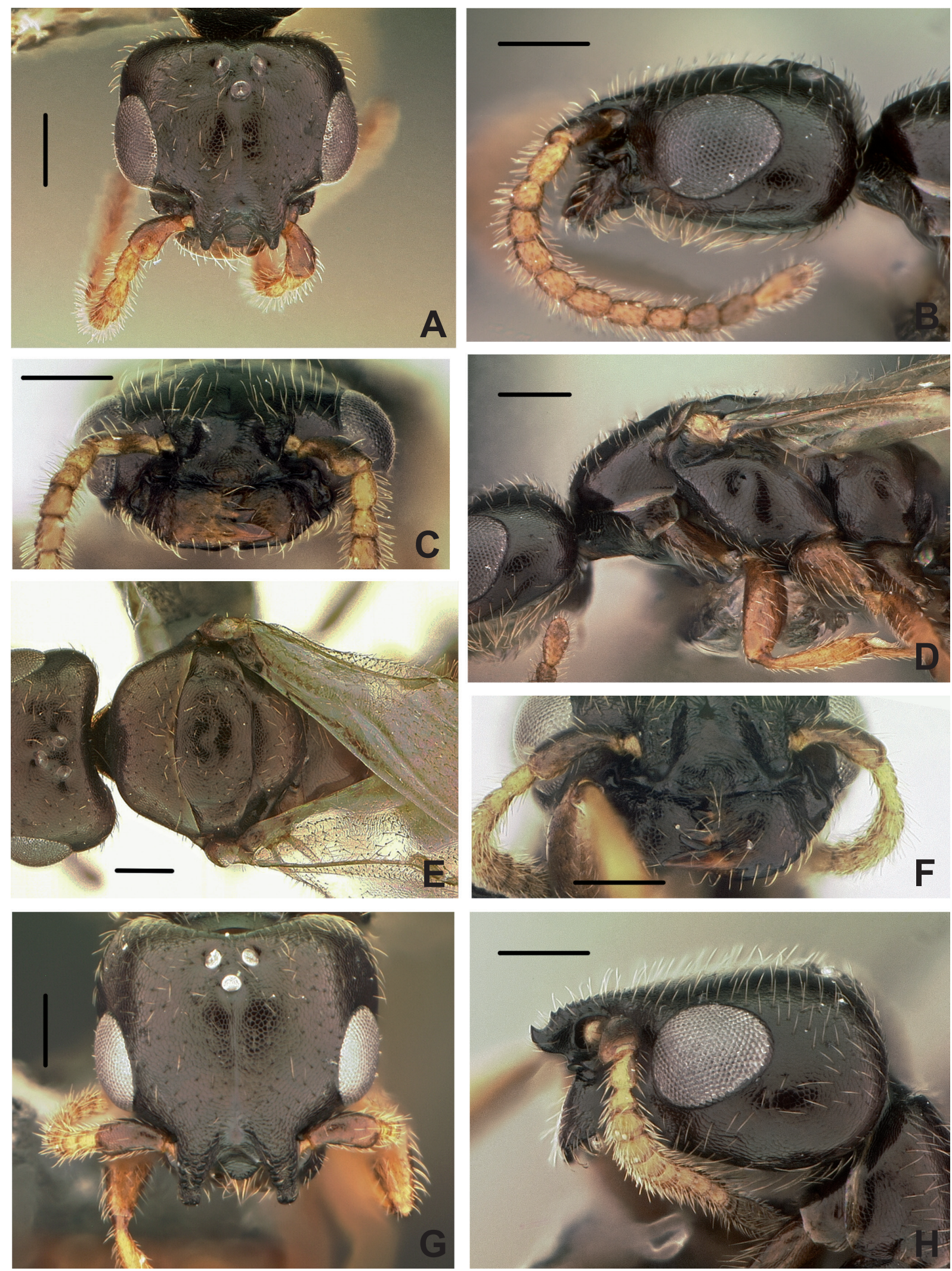

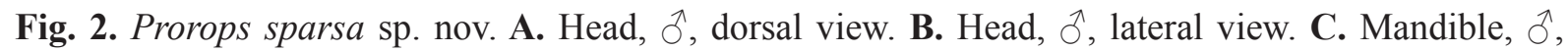
frontal view. D. Mesopleuron, $\hat{\jmath}$, lateral view. E. Mesosoma, $\hat{\partial}$, dorsal view. F. Mandible,, , frontal view. G. Head, $q$, dorsal view. H. Head, $q$, lateral view. - Scale $=0.2 \mathrm{~mm}$. 

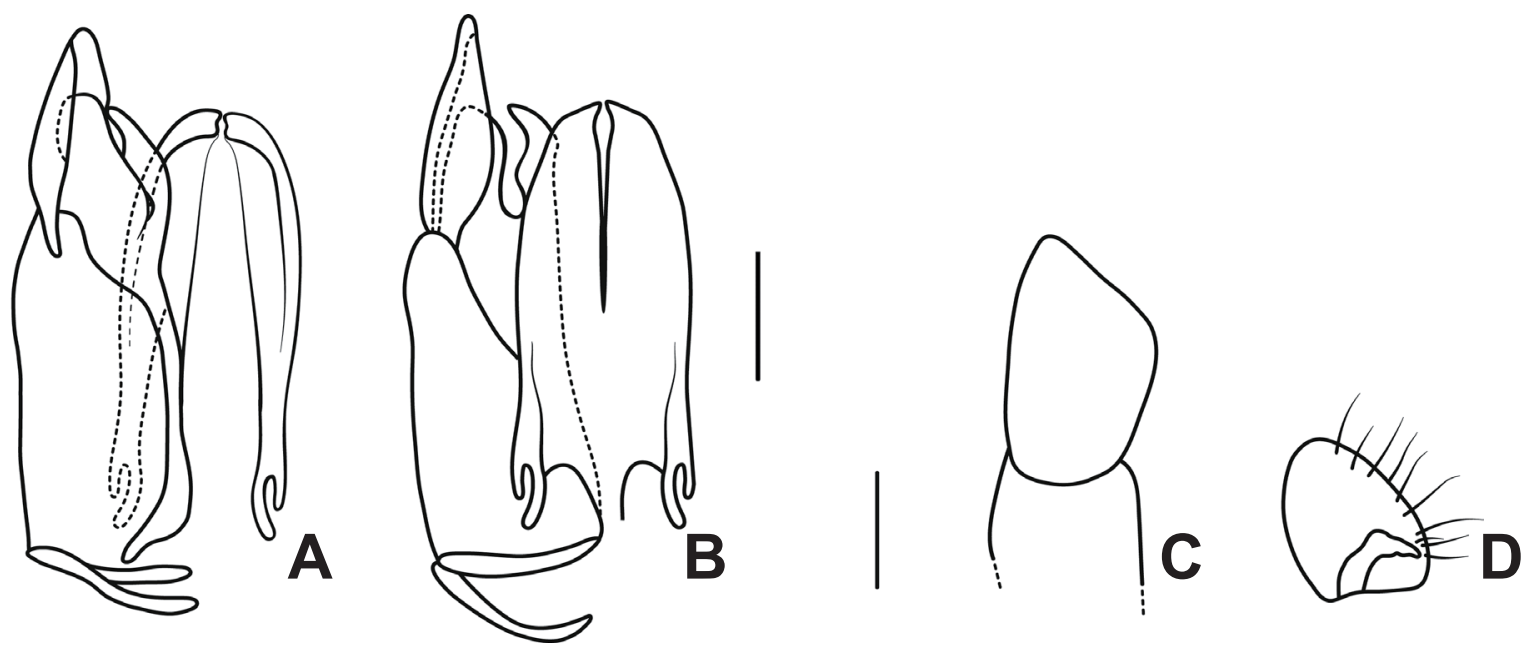

Fig. 3. Prorops sparsa sp. nov. đ̊ genitalia. A. Ventral view. B. Dorsal view. C. External face of paramere, lateral view. D. Internal face of paramere and digitus, lateral view. - Scale $=0.12 \mathrm{~mm}$.

CoLor. Head and mesosoma dark castaneous, metasoma castaneous; mandible dark castaneous; antenna castaneous, scape darker; legs castaneous, tibiae and tarsomeres lighter; tegula castaneous; wing subhyaline.

HeAD (Fig. 2A-C). Mandible wide, its width $0.8 \mathrm{x}$ eye width; three conspicuous apical teeth, two lower ones sharpened, uppermost tooth wide. Clypeus wide, short; median lobe rounded, crossed by transverse sharp ridge, delimiting broad posterior area with sub-horizontal and slightly concave surface, and anterior surface almost vertical; median carina absent; lateral lobes slightly developed. Antenna moniliform, first four segments in ratio of about 17:10:7:9; pedicel 1.6x as long as wide; flagellar pubescence suberectsubappressed, setae around $0.7 \mathrm{x}$ as long as segment diameter. Eye $1.45 \mathrm{x}$ as long as wide; setae sparse, minute. Frons coriaceous; punctures sparse, small, shallow; frontal line sulcate, 0.36x LH; frontal process entirely bifid, arms widely separated from each other, extending forward $0.35 \mathrm{x}$ torular diameter; cross-section elliptical, vertical, apex badly excavated dorsally; torulus circular, vertical. WH 1.26x LH; WF 0.66x WH; WF 1.65x HE; OOL 1.29x WOT; frontal angle of ocellar triangle acute, distance between posterior ocelli $0.35 \mathrm{x}$ WOT; distance from posterior ocellus to vertex crest $0.8 \mathrm{x}$ DAO. Vertex crest profile broadly convex. VOL $0.59 x$ HE.

Mesosoma (Fig. 2D, E). Thorax mostly coriaceous; punctured as frons. Pronotal disc with anterior margin sharp, not carinate, depressed medially. Notaulus absent. Parapsidal line almost complete, evenly slightly arched. Transscutal suture very narrow. Scutellar disc wide; scutellar groove absent; pits absent. Mesopleural pit conspicuous. Propodeum entirely coriaceous, disc $1.5 \mathrm{x}$ as wide as long, slightly narrowing posterad; anterior, posterior, discal and lateral carinae absent; spiracle placed laterally, lateral of propodeum with conical basal-posterior spine. Forewing with radial vein long, length $0.5 \mathrm{x}$ total forewing length, basal vein wide.

Metasoma. Mostly polished, about $1.4 \mathrm{x}$ as long as mesosoma. Hypopygium with median stalk $0.71 \mathrm{x}$ as long as plate, posterior margin narrowly straight, lateral margins strongly convergent posterad.

Genitalia (Fig. 4A-D). Paramere with subtriangular aspect in lateral view, wide, progressively narrowing apicad, apex acute; cuspis strongly setose, base wide, progressively narrowing to rounded apex; as high as $3 / 4$ of paramere; aedeagus with subrectangular aspect in dorsal view, with pair of apical lobes, apical margin rounded with inner corner acutely produced, apex almost aligned with cuspis apex; apodeme not 
extending beyond genital ring, base not dilated, bifurcated, inner arm slightly laterad and longer than outer arm.

Allotype, + . Similar to males, except for: Body length $3.46 \mathrm{~mm}$. Forewing length $2.0 \mathrm{~mm}$.

HEAD (Fig. 2F-H). Clypeus with median lobe subangulate, not crossed by transverse ridge, surface slightly convex, inclined. First four antennal segments in ratio of about 21:8:6:7. Eye 1.16x as long as wide; setae sparse, small. Frontal line $0.24 \mathrm{x}$ LH. Frontal process extending forward 1.1x torular diameter, apex strongly excavated dorsally with borders denticulate, tip curved dorsad. WH 1.0x LH; WF 0.72x WH; WF 1.84x HE; OOL 2.13x WOT; frontal angle of ocellar triangle very acute, distance between posterior ocelli $0.27 x$ WOT. Vertex crest profile broadly convex. VOL $0.78 x$ HE.

Mesosoma. Propodeal disc $1.7 \mathrm{x}$ as wide as long.

Metasoma. About 2.1x as long as mesosoma.

\section{Variation}

There is little variation among females. The general color can be lighter or darker; the general texture can be slightly more marked; the vertex crest profile can be straight or broadly concave; the frontal angle can be almost right; the frontal line can reach the anterior ocellus; the frontal process can be wider; the anterior margin of the pronotal disc can be rounded; the parapsidal lines can be absent anteriorly; and the basal-posterior spine of the propodeal disc can be absent.

The variation among the males is also tenuous. The general color can be lighter; the transverse ridge of the median clypeal lobe can be absent; the vertex crest profile can be straight; the frontal angle can be almost right; the frontal line can reach the anterior ocellus; and the frontal process can be shorter.

The sexual dimorphism is inconspicuous. The main differences are that females have the median clypeal lobe subangulate with a transverse ridge; the scape is proportionally longer in relation to other antennomeres; the eyes are wider with setae more conspicuous; the frontal process is proportionally longer with texture coarser; the frontal angle of the ocellar triangle is acuter; the vertex is more invaginate; and the metasoma is proportionally much longer than the mesosoma.

\section{Distribution}

Madagascar (Toamasina, Diego-Suarez, Fianarantsoa).

Prorops impotens sp. nov.

(Figs. 1B, 4A-F, 5A-C)

\section{Etymology}

The specific epithet refers to the delicate general aspect of the body.

Material examined (all from Madagascar)

\section{Holotype}

đ, Province Fianarantsoa, Parc National Ranomafana, radio tower at forest edge, elevation $1130 \mathrm{~m}, 16$ Oct.-8 Nov. $2001,21^{\circ} 15^{\prime} 05^{\prime}$ 'S $47^{\circ} 24^{\prime} 43$ 'E, Malaise trap, mixed tropical forest, R. Harin'Hala coll., MA-02-09B-01, CASENT 2085910 (CASC). 

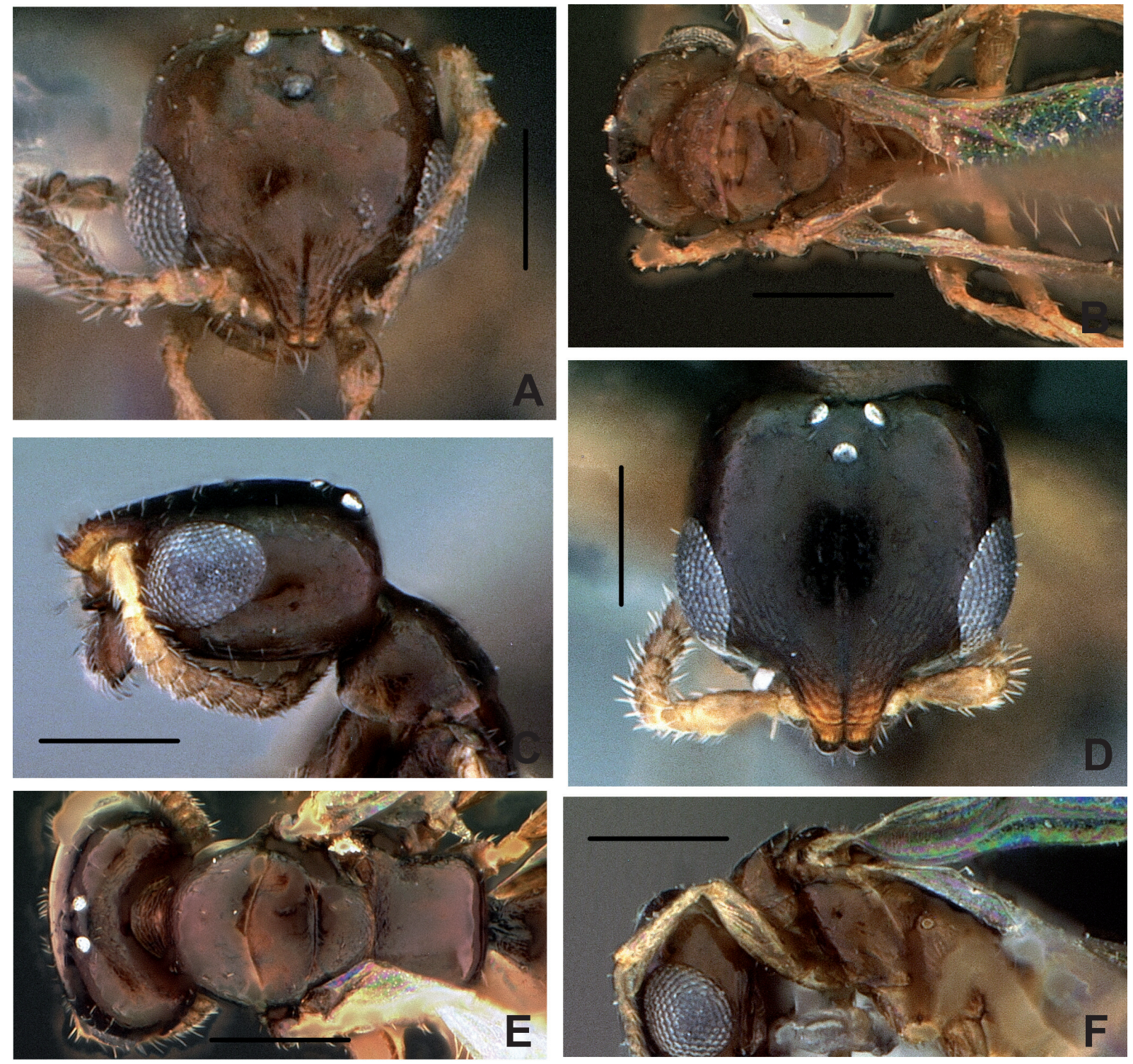

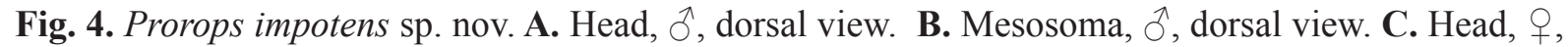
lateral view. D. Head, $q$, dorsal view. E. Mesosoma, + , dorsal view. F. Mesopleuron, $q$, lateral view. Scale $=0.2 \mathrm{~mm}$.

\section{Allotype}

9 , Toliara Province, Manderano, elevation $70 \mathrm{~m}$, edge of marsh, $5 \mathrm{~m}$ from road, 23 Jun.-28 Jul. 2002, $23^{\circ} 31^{\prime} 39^{\prime \prime}$ S $44^{\circ} 5^{\prime} 18^{\prime}$ E, Malaise trap, gallery forest, Frontier Wilderness Project coll., MGF 036, CASENT 2083424.

\section{Paratype}

1 , same data as allotype, MGF 035, CASENT 2078918.

\section{Diagnosis}

This species is recognized by having a dark castaneous color, except the scape, pedicel, palpi, and legs, which are castaneous; the wing is hyaline; the head is about as wide as long; the mandible is covered 

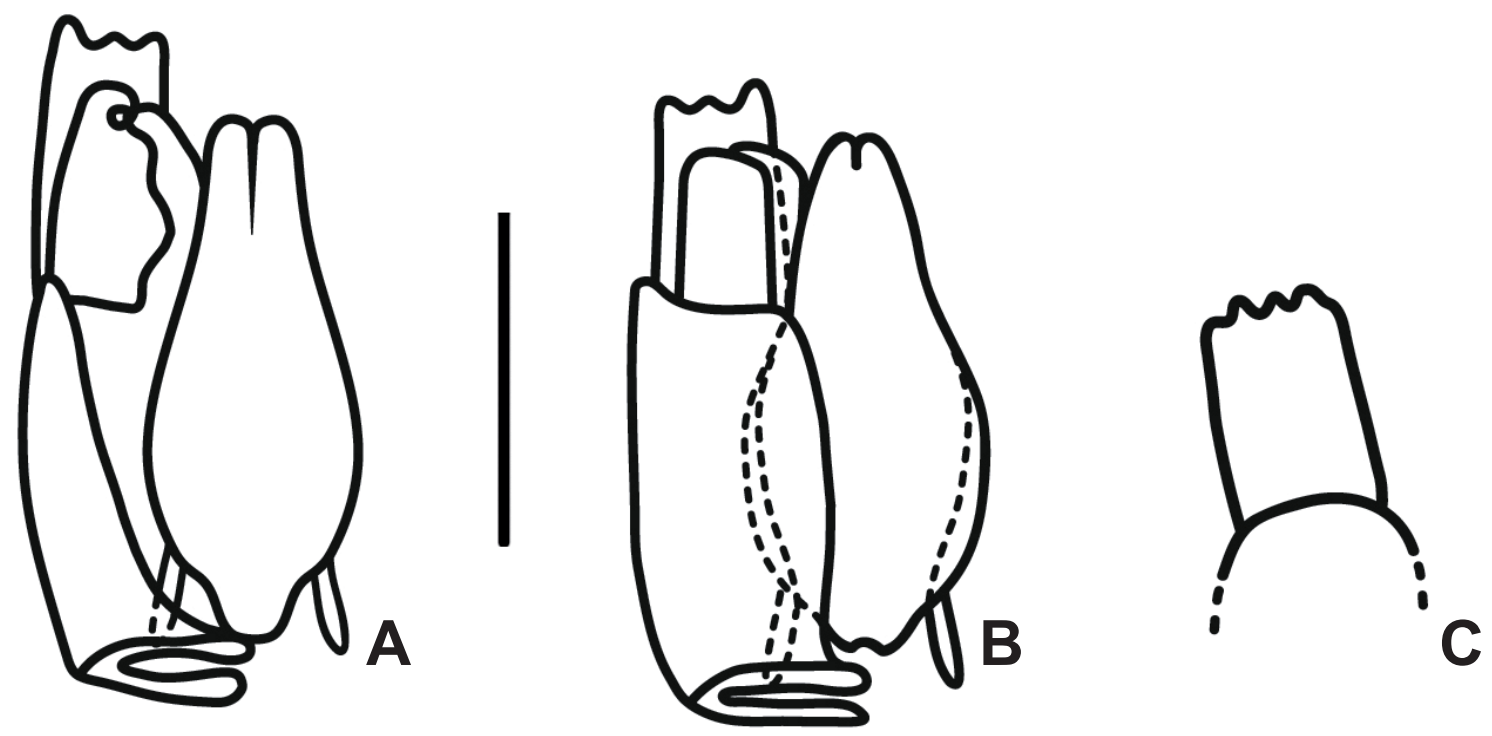

Fig. 5. Prorops impotens sp.nov. $\widehat{\partial}$ genitalia. A. Dorsal view. B. Ventral view. C. External face of paramere, lateral view. - Scale $=0.12 \mathrm{~mm}$.

by the frontal process and not visible; the frontal process is elongated, joint and bifid; the mesoscutum without parapsidal sulcus; the propodeum without carina; and the fore wing without radial vein.

\section{Differential diagnosis}

This species is distinct from P. sparsa by having the frontal process joined and the forewing with radial vein, while in P. sparsa the frontal process is separated and the radial is absent. Prorops impotens is morphologically close to $P$. obsoleta because of the absence of the radial vein on the forewings (Fig. 1B). Prorops impotens, however, has a bifid frontal process, whereas it is somewhat triangular in P. obsoleta.

\section{Description}

Holotype, $\widehat{\jmath}$. Body length $0.81 \mathrm{~mm}$. Forewing length $0.81 \mathrm{~mm}$.

CoLor. Head, mesosoma, metasoma, mandible, flagellomeres, and tegula somewhat dark castaneous; scape, pedicel, palpi, and legs castaneous, tibiae and tarsomeres lighter; wings hyaline.

HeAd (Fig. 3A). Mandible wide, its width $0.83 x$ eye width, with apparently four sharpened apical teeth, upper two small, lower two conspicuous. Clypeus with median lobe trapezoidal, surface almost vertical, median carina absent, apical margin arched dorsad medially in frontal view, lateral lobe almost absent. Antenna moniliform, first four segments in ratio of about 4:2:1:1; pedicel 1.5x as long as wide, flagellar pubescence suberect, setae around $0.7 \mathrm{x}$ as long as segment diameter. Eye 1.1x as long as wide; setae short, sparse. Frons polished; punctures sparse, small, shallow; frontal line sulcate, $0.5 \mathrm{x} \mathrm{LH}$; frontal process coriaceous, shortly bifid, extending forward about 1.0x torular diameter, apical surface concave, tip curved dorsad; torulus circular, vertical. WH 1.03x LH; WF 0.6x WH; WF 1.24x HE; OOL 1.18x WOT; posterior ocellus touching vertex crest, frontal angle of ocellar triangle about right, distance between posterior ocelli $0.55 \mathrm{x}$ WOT. Vertex crest profile almost straight. VOL $0.57 \mathrm{x}$ HE.

Mesosoma (Fig. 3B). Thorax mostly polished; punctures inconspicuous. Pronotal disc with anterior margin rounded in lateral profile. Notaulus and parapsidal line absent. Transscutal suture very narrow. 
Scutellar disc wide; scutellar groove absent, pits absent. Propodeum polished, disc about 1.1x as wide as long, progressively narrowing posterad; anterior, posterior, discal and lateral carinae absent; spiracle placed laterally. Mesopleuron with central pit conspicuous. Forewing only with stigma, subcostal, and basal veins; basal vein wide.

Metasoma. Polished, about as long as mesosoma.

Genitalia (Fig. 5A-C). Paramere with subquadrate aspect in lateral view, wide, almost evenly wide apicad, apical margin slightly inclined and waved; cuspis strongly setose, evenly very wide, apical margin almost blunt, its apex aligned with about $0.8 \mathrm{x}$ of paramere length; aedeagus bottle-shaped, its apex aligned with cuspis apex, with one pair of rounded apical lobes; apodeme slender, not extending beyond genital ring, base not dilated.

Allotype, + . Similar to males, except for: Body length $1.15 \mathrm{~mm}$. Forewing length $0.92 \mathrm{~mm}$.

Color. Head, mesosoma, metasoma, mandible, and tegula dark castaneous.

HEAD (Fig. 3C-D). Eye 1.27x as long as wide. Frontal line reaching anterior ocellus. WH 0.96x LH; WF $0.88 x$ WH; WF 2.0x HE; OOL $1.73 x$ WOT. Vertex crest profile slightly concave. VOL $0.84 x$ HE.

Mesosoma (Fig. 3E-F). Propodeal disc $0.7 \mathrm{x}$ as wide as long, lateral carina fully outlined; sides of propodeum weakly coriaceous.

Metasoma. 1.3x as long as mesosoma.

\section{Variation}

The variation among the females is tenuous. The general color can be lighter and the eyes shorter; the frontal line can be as long as in the male; the posterior ocellus in some specimens does not reach the vertex crest. The sexual dimorphism is very weak as well. The main difference is that in females the propodeal disc has lateral carinae, the vertex crest is slightly concave, and the metasoma is proportionally much longer than the mesosoma.

\section{Distribution}

Madagascar (Toliara, Fianarantsoa).

\section{Prorops nasuta Waterson, 1923}

Prorops nasuta Waterson, 1923: 113-114, figs. 5-6.

\section{Material examined (all from Madagascar)}

1 q, Province d'Antananarivo, botanic garden, near entrance to Andasibe National Park, elevation 1026 m, tropical forest, 1-5 Sep. 2001, 1955'59' S 48²4'49”E, Malaise trap, R. Harin'Hala coll., MA0108B-11, CASENT 2061637 (CASC); 1 , , Province Diego-Suarez, Parc National Montagne d'Ambre, elevation 1125 m, 30 May-6 Jun. 2001, 12³1'13”S 49¹0’45”E, Malaise trap, R. Harin'Hala coll., MA-01-01D-12, CASENT 2087898.

\section{Remarks}

This is the first record of this species for Madagascar. 


\section{Key to males and females of Prorops from Madagascar}

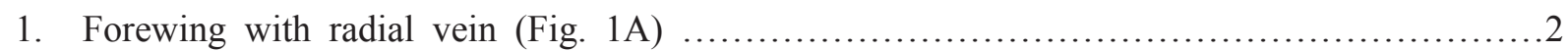

- Forewing without radial vein (Fig. 1B) ............................ impotens sp. nov. $(\Varangle \widehat{\dagger})$

2. Frontal process entirely divided into two arms, arms broadly separated from each other (Fig. 2A, G) …............................................ sparsa sp. nov. (q

- Frontal process not divided, rounded forward .................... nasuta Waterson, 1923 (†

\section{Discussion}

Mugrabi \& Azevedo (2011) recorded Prorops for the first time for the Malagasy region. Here, we add three species to the known list of fauna of Prorops in Madagascar. The genus is now known to comprise seven species.

The original distribution of Prorops remains unclear. The expansion of coffee crops throughout the world has contributed to the introduction of $P$. nasuta in different tropical areas. In addition to distribution of coffee crops, these tiny bethylid wasps could have been introduced to different regions of the world through other trade ventures. Evans (1977), for example, suggested that P. obsoleta and P. petila could have been brought to the Americas by commercial activities. Introduced populations of P. nasuta, however, have been poorly established in different countries where they are used for biological control (Infante et al. 2005).

Specimens of Prorops are very diminute and the presence of large and strong mandibles suggests that individuals have to make their way through hard substrate to find their hosts/mates. They seem to be specialized to live in small habitats and openings of galleries in hard tissues, such as grains. The elongated frontal process might have a role in this as well. Prorops sparsa is the only known species of Prorops in which the frontal process is separated.

A lack of tegumental characteristics in Prorops, however, has interfered in species delimitation and evolutionary studies. The main diagnostic features used in differentiating the species of Bethylidae, such as carinae, furrows, and alar veins, are not present. Species delimitation in Prorops has relied exclusively on the presence of the radial vein and the shape of the head and frontal process (Evans 1977; Terayama 2006). The increased number of species and specimens available for study suggests that these historical characters are dubious. Furthermore, coloration, shape of the body and head, and the apex of the frontal process vary among individuals from different localities. Future studies are necessary to better define and delimit the species of Prorops.

Madagascar is estimated to have had more than $80 \%$ of its original habitat destroyed; most of the island is now composed of secondary vegetation (Fisher \& Robertson 2002). Three species, two of which are new to science, recorded from this island demonstrate the high level of Malagasy diversity and the overall unknown status of its fauna. Although our material originated from a wide and long-term survey, we believe that even more species have yet to be described for the region.

\section{Acknowledgements}

We thank Robert Zuparko and Brian Fisher for the loan of material examined; Conselho Nacional de Pesquisa e Tecnologia (CNPq) grants \#303216/2004-2, \#306231/2007-7, \#502656/2007-7 and 301669/2010-4 for the fellowships provided to COA; CNPq grants \#563953/05-5, 474116/20034, 473386/2008-9, 473386/2008-9, 502958/2008-1 and 501185/2010-0; and Fundação de Amparo à Pesquisa do Espírito Santo (FAPES) grants \#39353842/07, \#41106407/08 and \#45429065/2009 for 
their financial support. We also thank the Programa de Taxonomia for CNPq grant \#563953/05-5 and the Programa Casadinho for CNPq grants \#620064/2006-4 and 620068/2008-6. We also thank Emily Sadler for reviewing the manuscript, and Daniele F. Mugrabi and Diego N. Barbosa for providing the illustrations.

\section{References}

Azevedo C.O. 1999. Bethylidae In: Brandão, C.R.F. \& Cancello, E.M. (eds.) Biodiversidade do Estado de São Paulo: Síntese do conhecimento ao final do século XX. São Paulo, FAPESP, xviii+279pp.

Evans H.E. 1964. A synopsis of the American Bethylidae (Hymenoptera, Aculeata). Bulletin of the Museum of Comparative Zoology 132: 1-222.

Evans H.E. 1977. A further look at the genus Prorops (Hymenoptera, Bethylidae). New York Entomological Society 85: 50-54.

Fisher B.L. \& Robertson H.G. 2002. Comparison and origin of forest and grassland ant assemblages in the high plateau of Madagascar (Hymenoptera: Formicidae). Biotropica 34(1): 155-167. http://dx.doi. org/10.1646/0006-3606(2002)034[0155:CAOOFA]2.0.CO;2

Harris R.A. 1979. A glossary of surface sculpturing. Occasional Papers in Entomology 28: 1-31.

Infante F., Mumford J. \& Baker P. 2005. Life history studies of Prorops nasuta, a parasitoid of the coffee berry borer. BioControl 50: 259-270. http://dx.doi.org/10.1007/s10526-004-1115-7

Lim J. \& Lee S. 2011. A new species of Prorops Waterson 1923 (Hymenoptera: Bethylidae) from Cambodia with a key to world species. Zootaxa 3040: 25-28.

Mugrabi D.F. \& Azevedo C.O. 2011. Insecta, Hymenoptera, Bethylidae: Range extension and filling gaps in Madagascar. Check List 6(1): 62-63.

Murphy S.T. \& Moore D. 1990. Biological control of the coffee berry borer Hypothenemus hampei (Ferrari) (Coleoptera: Scolytidae), previous programmes and possibilities for the future. Biocontrol News and Information 11: 107-117.

Pérez-Lachaud G. \& Hardy I.C.W. 1999. Reproductive biology of Cephalonomia hyalinipennis (Hymenoptera: Bethylidae), a native parasitoid of the coffee berry borer, Hypothenemus hampei (Coleoptera: Scolytidae), in Chiapas, Mexico. Biological Control 14:152-158.

Terayama M. 2006. The Insects of Japan. Vol. 1. Bethylidae (Hymenoptera). Touka Shobo Co. Ltd., Fukuoka.

Waterston J. 1923. Notes on parasitic Hymenoptera. Bulletin of Entomological Research 14:103-118. http://dx.doi.org/10.1017/S0007485300028248

Manuscript received: 30 January 2012

Manuscript accepted: 29 May 2012

Published on: 26 June 2012

Topic editor: Koen Martens

In compliance with the $I C Z N$, printed versions of all papers are deposited in the libraries of the institutes that are members of the EJT Consortium: Muséum National d'Histoire Naturelle, Paris, France; National Botanic Garden of Belgium, Meise, Belgium; Royal Museum for Central Africa, Tervuren, Belgium; Natural History Museum, London, United Kingdom; Royal Belgian Institute of Natural Sciences, Brussels, Belgium; Natural History Museum of Denmark, Copenhagen, Denmark. 